\title{
A espontaneidade no cenário da psicologia contemporânea
}

\section{Spontaneity in the scenary of contemporary psychology}

\author{
Luciana Loyola Madeira Soares* \\ Universidade do Estado do Rio de Janeiro - UERJ, Rio de Janeiro, Rio de Janeiro, \\ Brasil
}

Baptista, M.C.V.D (Org.)(2012). O palco da espontaneidade Psicodrama Contemporâneo (266p). São Paulo: Roca.

Este livro reúne a produção dos mais destacados e atuantes psicodramatistas brasileiros, em sua maioria do Rio de Janeiro. Sua realização é a materialização dos esforços das diretoras do Delphos espaço psicossocial, entidade que atualmente lidera em solo carioca a prática, a divulgação e a transmissão do legado teórico e terapêutico de Jacob Levy Moreno - o criador do sistema psicodramático. Com a organização de Maria Cecília Veluk Dias Baptista, bem de acordo com a perspectiva moreniana de co-criação, juntam-se a Lilian Tostes, Ducarmo Mendes e Nice Brandão, os autores Carlos Rubini, Heloísa Fleury, Jorge Maurício Reis, Jorgelina Carvalho, Beatriz Weeks, Lúcia Vidal, Maria Rita Seixas, Marlene Marra, Mary de Barros, Rosita Koshar, Vitória Pamplona e Yvette Datner. Todos estes autores têm dado relevante contribuição ao cenário do Psicodrama, e ao campo das psicoterapias em geral, ao longo de seus diferentes percursos profissionais, tanto em suas práticas quanto através de publicações e participações em congressos. A própria organizadora, Cecília Veluk, já figura como autora de capítulos de vários outros livros de Psicodrama e de Terapia de Família. Os temas escolhidos - abrangentes e extremamente afinados com as questões e temas mais pulsantes na clínica contemporânea e nos diferentes contextos sociais - propõem uma ampla retomada aos postulados morenianos em um enfoque que põe em evidência a viva articulação e o diálogo do Psicodrama com outros campos do conhecimento e de intervenção.

Para relembrar...

Nascido na Europa no início do século XX e com uma prática consolidada nos Estados Unidos a partir da década de 30, o Psicodrama chega ao Brasil em fins dos anos 60, tempo de repressão, e época em que outras abordagens com atitude de 'contracultura' 
também eram aqui recebidas, como a Gestalt-terapia, por exemplo. Tais abordagens encontraram no ambiente psicoterápico brasileiro solo fértil para a expansão de caminhos terapêuticos que acenavam com a perspectiva de uma atitude clínica que tanto incluía o verbal numa perspectiva dialógica, quanto o corpo de modo criativo, desdobrando-se em intervenções grupais calcadas numa ética comprometida com a transformação no contexto das práticas em Psicologia dentro e fora dos consultórios, tais como hospitais, escolas e organizações em geral. Ao longo dos anos, tais abordagens tomaram rumos próprios, conquistando no país espaço não apenas na prática das intervenções, mas, também, no cenário da produção teórica, inclusive acadêmica. Nas universidades já contamos há algumas décadas com professores e pesquisadores, mestrandos e doutorandos inspirados e fundamentados nestas linhas de intervenção e de produção teórica em Psicologia. O Psicodrama, em particular, firmou-se nos vários contextos de intervenção supracitados, sendo praticado não apenas por psicólogos, mas, também, por profissionais de outras carreiras, como pedagogos, médicos, enfermeiros, administradores, que têm recorrido à formação psicodramática para ampliar seus horizontes profissionais.

Após o prefácio de José Fonseca Filho, vem a Introdução a cargo de M. Cecília Veluk, que nos apresenta o livro contando um pouco da história de sua concepção e elaboração - um sonho empurrado para a realidade, bem ao gosto de Moreno. Os primeiros cinco capítulos preparam o leitor alimentando-o com uma revisão da obra moreniana à luz da contemporaneidade e de um modo brasileiro de praticá-la. É interessante observar que cumprem uma função de 'aquecimento' tal como se inicia um processo de dramatização; são eles: 'O palco cósmico' e 'Moreno Contemporâneo' de Maria Lúcia Vidal; 'Papel, identidade e psicodrama', de Carlos Rubini; 'As etapas da psicoterapia psicodramática desveladas pela literatura', de Maria Beatriz Weeks; 'Reflexões sobre a identidade e a ética psicodramática', de Maria Cecília Veluk.

Os demais treze capítulos abordam diferentes relatos de experiências de psicodramatistas que percorrem temáticas específicas em criativas articulações com outros campos do conhecimento; um convite à dramatização, a saber: 'O psicodrama na preparação do casal grávido para as vivências de maternidade/paternidade', de Vitória Pamplona; 'A contribuição do psicodrama ao processo de coaching', de Mary de Barros; O método e a técnica psicodramática aplicados à terapia sexual', de Jorge Maurício Reis; 'Psicodrama com crianças e a relação fraterna', de Rosita Koschar; 'Mulheres vítimas de violência sexualafeto, humor e respeito na psicoterapia', de Nice Pereira Brandão; 'A espontaneidade como fator de libertação na psicoterapia de um caso de segredo na relação terapeuta e cliente', de Lilian Tostes; 'Direção de um grupo de apoio mútuo a familiares e portadores da síndrome 
de von Recklinghausen', de Maria do Carmo M. Rosa; 'O uso do EMDR e do psicodrama no tratamento psicoterápico', de Jorgelina Carvalho; 'Revisitando as histórias familiares por meio do genodrama', de M. Cecília Veluk; 'Neurociência, psicodrama e o processo de mudanças', de Heloísa Fleury; 'Ressonância e resiliência: conceitos que ampliam a função do grupo em contextos relacionais', de Marlene Magnabosco Marra; 'O conceito de consciência sociométrica no desenvolvimento de relações grupais saudáveis nas organizações', de Yvette Datner; 'Quando a família não é um sonho possível: a dramatização reveladora', de Maria Rita Seixas.

Destacamos os dois primeiros capítulos, nos quais Maria Lúcia V. Mello introduz o leitor à visão moreniana através de uma contraposição à visão iluminista que vem associada à lógica do liberalismo econômico. Ao longo destes capítulos a autora faz uma revisão do pensamento de Moreno como apontando para o envio da pós modernidade. A expansão do Psicodrama para a clínica não o afastou do campo das práticas sociais, como podemos constatar em suas afinidades com os mais recentes desenvolvimentos em Psicologia Social pautados numa perspectiva de coletivos tecidos em redes. Mello, assim como os demais autores que a acompanham neste livro, enfatiza as possibilidades de diálogo de Moreno com L. Boff, E. Morin, F. Capra e com diversos campos do conhecimento, como a espiritualidade, o pensamento complexo, a ecologia, 0 pensamento sistêmico, etc. A conexão de Moreno com o mundo atual através destas redes de 'co-criação' desdobra-se em novas possibilidades de ação, e se presentifica nos demais textos do livro.

A partir da leitura destes dezoito capítulos confirmamos a genialidade de Moreno como precursora de uma visão de homem como ser ativo, criativo, de múltiplas conexões, nas quais e a partir das quais dialogicamente se sustenta e se renova, assim como também renova e dá sustentação às suas relações. Nestes textos, o Psicodrama, sua história, seus conceitos, técnicas, fundamentação teórica e filosófica são apresentados num fluxo processual de modo a contar e recontar estórias através dos diferentes olhares e fazeres de seus narradores. Como 'drama' é ação, os autores deram prosseguimento ao trabalho criado por Moreno, indo para a ação, criando mundos a partir de suas intervenções. Trabalhando no campo, fertilizaram-no com a fundamentação teórica psicodramática de modo a torná-lo cada vez mais ativo, criativo e produtivo.

Fazer referência a esta obra apenas como uma compilação não a traduz fielmente, pois é melhor descrevê-la como um harmonioso conjunto de versões que, ao serem apresentadas, põem em cena as noções morenianas configurando um verdadeiro processo de dramatização ao qual o leitor é convidado a participar ao ser afetado pelo movimento das práticas e reflexões. As narrativas tanto contemplam o leitor com consistência teórica, filosófica e conceitual, 
quanto tem a competência de emocionar, bem de acordo com o que Moreno sensivelmente percebeu ao conceber um sistema teórico e técnico que era capaz de afetar os participantes que compunham a rede relacional das dramatizações que conduzia na Viena de sua época.

Extremamente fiéis a J. L. Moreno, os autores imprimem a seus textos a marca da integração harmoniosa entre informalidade, criatividade, renovação e seriedade no trato teórico e no prático, que tanto caracterizam a obra moreniana, o que não nos deixa dúvida acerca da atualidade e da condição de vivacidade da abordagem no Rio de Janeiro e no Brasil. Trata-se de um livro indicado a quem deseja aproximar-se ou reaproximar-se do Psicodrama, assim como atualizar-se a respeito de suas aplicações na contemporaneidade e possiblidades de interface com outras abordagens.

\section{Endereço para correspondência \\ Luciana Loyola Madeira Soares}

Universidade do Estado do Rio J aneiro

Programa de Pós-Graduação em Psicologia Social

Rua São Francisco Xavier, 524 10 andar, Pavilhão João Lyra Filho, Maracanã, CEP 20550-900, Rio de Janeiro - RJ, Brasil.

Endereço eletrônico: psi.lucianasoares@gmail.com

Recebido em: 12/05/2013

Reformulado em: 14/04/2014

Aceito para publicação em: 26/04/2014

\section{Notas}

* Doutoranda do Programa de Pós-Graduação em Psicologia Social da Universidade do Estado do Rio de Janeiro, RJ, Brasil. Professora da graduação em Psicologia do Instituto Brasileiro de Medicina de Reabilitação - IBMR. Professora da Graduação em Psicologia do Centro Universitário Celso Lisboa - Rio de Janeiro, RJ, Brasil. Membro do Laboratório Gestáltico - configurações e práticas contemporâneas, da Universidade do estado do Rio de Janeiro, RJ, Brasil. 